\title{
The Agonies and Glories of Female Domestic Workers in the Gulf States: Experiences of Ex-migrants in Northern Ethiopia
}

\author{
Kelemework Tafere Reda \\ Visiting Researcher, Institute of Dispute Resolution in Africa (IDRA), University of South Africa \\ (UNISA) E-mail: ktreda@unisa.ac.za
}

\begin{abstract}
Women's response to poverty and unemployment is a major concern for policy makers. One of the most prominent livelihood strategies used by poor, unemployed and uneducated women in Northern Ethiopia is migration to the Middle East to earn money to support their families back home. Based on qualitative data, the study looks into migrant women's pre-and post-migration scenarios in terms of their economic, social and psychological wellbeing. The pull and push factors, the challenges and opportunities as well as the pattern of decision making are examined. The migration of large number of women domestic workers into the Gulf States is propelled by the need to earn income to support family and save money to start small businesses in their places of origin. Peer pressure and family influence are also found out to be crucial factors in migration. Despite marginal socio-economic gains, migrants are subject to incidents of domestic violence, rape, harassments or even murder. This calls for an integrated and concerted multistakeholder effort to empower women through sound policies and interventions.
\end{abstract}

Keywords: Women, Poverty, Ethiopia, Migration, Middle East

\section{Résumé}

La réponse des femmes à la pauvreté et au chômage est une préoccupation majeure pour les décideurs politiques. La migration vers le Moyen Orient est l'une des stratégies de subsistance la plus importante utilisée par les femmes pauvres, sans emploi et non éduquées au Nord de l'Ethiopie pour gagner un revenu pouvant leur permettre de soutenir leurs familles restées au pays. Basé sur des données qualitatives, l'étude se penche sur les scénarios pré- et post-migration des femmes migrantes en termes de leur bien-être économique, social et psychologique. Les facteurs de tirer et de pousser les défis et les opportunités ainsi que le motif de la prise de décision sont examinés. La migration d'un grand nombre de femmes domestiques travaillant dans les Etats du Golfe est motivée par la nécessité de gagner un revenu pour soutenir la famille et économiser de l'argent afin de commencer le petit commerce dans leurs lieux d'origine. La pression des pairs et l'influence de la famille sont également découvertes comme étant des facteurs cruciaux dans la migration. Malgré les gains socio-économiques marginales, les migrants sont souvent victimes des actes de violence domestique, du viol, du harcèlement ou même de meurtre. Ceci appel pour un effort multipartite intégré et concerté pour l'autonomisation des femmes à travers d'interventions politiques complètes.

Mots-clés: Femmes, pauvreté, Ethiopie, Migration, Moyen-Orient

\section{Introduction}

Various authors have classified human migration into different categories. According to Cohen (1996) and King (20I2) such migration binaries or dichotomies as internal vs international, temporary vs. permanent, regular vs irregular, voluntary vs forced, economic migrants vs refugees should not be viewed as hard and fast classifications. International migration has become the order of the day over the past couple of decades and is being practiced in a way that facilitated globalisation, feminist outlooks, and diverse political views (Castle and miller 1993). Mobility has become a common practice for everyone (Cresswell 2006). According to recent statistics from the UN, there are 2I 4 million international migrants across the globe. If those living in a country other than their own form up a new a country, they would make up the fifth largest country in the world after china, India, USA and Indonesia (King 20I2). On the other hand, other authors argue that 214 million people are insignificant as this hardly represent over 3 per cent of the world's population. Although the number of migrants is 
growing substantially in recent years, the overall population growth globally has also prove to be tremendous and the percentage share remains low (ibid 20I2).

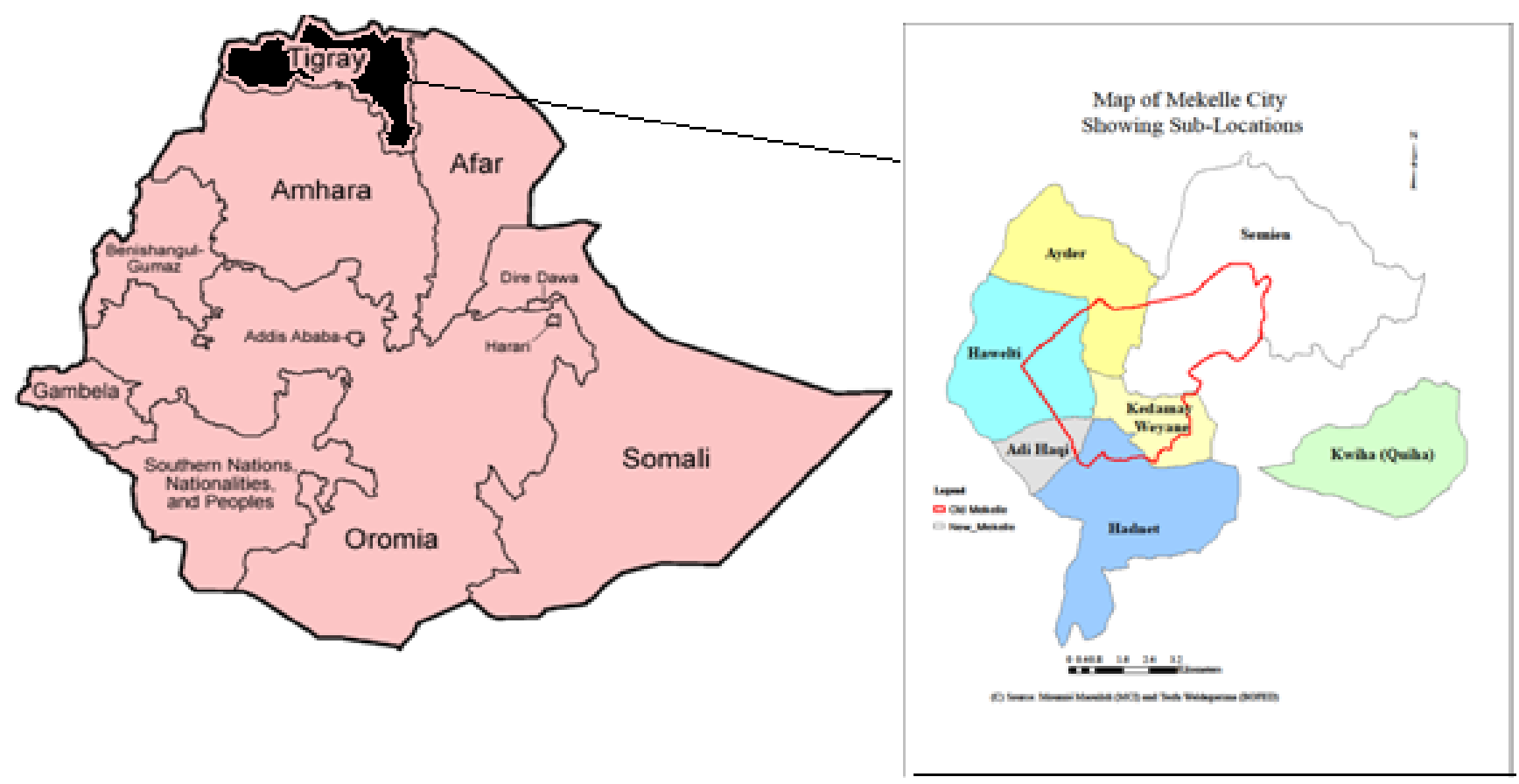

Figure I: Administrative map of Ethiopia and the research site (source: Castro et al. 2009)

International migration to the Gulf States has been common since the early 1970's which marked an economic boom resulting from discovery of oil deposits in the region (GTZ 2006). While the fall in the oil price during the 1980's substantially hampered employment in this sector, the demand for labour in other sectors (e.g. hotel and unskilled domestic work) increased, allowing the influx of a large number of migrants both from Africa and Asia. Changing lifestyles of people in the region has paved the way for better employment opportunities for people in Africa. According to Sutar (2005), most countries in the gulf region opened their doors for temporary labour migration while adopting a policy of intolerance toward permanent settlement or citizenship.

The study set out with the principal research questions:

- What are the incentives and disincentives in women's migration overseas?

- What are the micro-level dynamics in decision making regarding out-migration, resettlement and reintegration?

- Examine the challenges and opportunities associated with being a migrant worker in the gulf region

- Examine problems related to reintegration of exmigrants

- Suggest possible policy options with regard to the way forward.

\section{Literature review}

The concept of migration has been defined in many ways. Some authors (e.g. Datta 2004) define migration in terms of the movement of people from one geographic territory to another across or within national boundaries. Accordingly, migration may take place because of a number of push and pull factors and takes two forms: Voluntary and Forced. Economic hardships, civil strife violent conflicts, and environmental degradation are some of the push factors that create a sense of dissatisfaction among citizens of developing countries ultimately leading to displacement. On the other hand pull factors are those factors that attract people from faraway places in anticipation of improved livelihood conditions, employment opportunities and freedom (Dorigo \& Tobler 1983, Datta 2004). Nevertheless, international migrants should not be perceived as a homogeneous groups as there are different categories of people in post-modern migrations including seasonal and temporary workers, refugees and asylum seeks, skilled and unskilled labourers, legal and illegal migrants as well as permanent settlers (Shuval 200I).

International migration is affected by changes in the global economy (Shuval 200I). Receiving countries have different policies on cross-border migration but such countries tend to be selective in admitting migrants. The need to admit a mass of migrants apparently emanates from labour shortages in receiving countries. However, numerous admissions 
have also taken place on purely humanitarian grounds creating a favourable atmosphere for illegal migrations. The increasing need for cheap labour in receiving countries coupled with a multitude of push factors in poorer nations has made it difficult to control illegal migration (lbid 200I).

\section{Women and international migration}

Women's subordinate status in developing countries and the resultant low access to fundamental resources and opportunities (such as access to education, employment, etc.,) leaves them without any credible livelihood option. Therefore they ultimately decide to move to other countries as migrants in order to earn income to support their family members (Martin 2007, Steady 2006).

Women's migration is currently one of the most topical issues in the research and development discourse across the world. There are an estimated 190 million migrants across the globe of which women constitute almost half. Majority of the migration cases take place within the sphere of developing countries (movement from and to developing countries). There has been an increasing trend women labour migration across the globe particularly since the 1960's due to the restructuring of the global economy (Hochschild 2003 Isaksen et al 2008). According to current figures of the UN, about 40 per cent of all migrants since 2000 were women. Women migrants may move out as marriage partners or even on their own to earn wage. Sometimes, women may also decide to migrate because of conflict, political persecution, poverty or natural calamities that threaten their livelihood. Gender inequality is a powerful factor in migration and women move out to other countries when they are unable to meet the economic, social and political expectations in their own countries. The outcomes of women's migration depends on a number of factors including whether their movement was voluntary or forced or whether they entered countries of destination legally or illegally(Hochschild 2003).

On one hand, women's migration has some positive outcomes. Some scholars, (e.g. Isaksen et al 2003) argue that international migration brings hard currency to sending countries with a trickledown effect on family members of migrants who obtain remittances. Receiving countries also enjoy productive labour which is instrumental for stimulation of their economy. According to ILO (2003) migrant workers contribute significantly to foreign exchange earnings in their respective countries. For example, in some Asian countries such as Sri Lanka about $62 \%$ of the overall money sent home as remittances in the late 1990's came from international labour migrants. Much of the money is used to support family members at home including the migrants' own children of migrants (lbid,
2003). It is also worth noting that most of the recipients of remittances also tend to be women and is therefore linked to economic empowerment of women (Ramirez et al 2004). As a result, migration should be linked up with poverty reduction and socioeconomic growth in many developing countries although little is known about the gender-migrationpoverty reduction nexus (Lucas 2004, Adams 2005).

On the other hand, women migrants (especially those who migrate illegally) have been victims of human trafficking. They have been exposed to exploitation, coercion and abuse of power which contribute to further exacerbation of existing gender inequalities (UNHCR, 1990). Exploitation is often manifested in obligation to accept any kind of job or/and work under any living conditions (Suter 2005). They are often afraid of reporting injustices because to avoid the risk of expulsion (ibid 2005). Problems associated with using illegal employment agencies include irregularities with contractual agreements (about working hours, salary, freedom of movement, type of work, etc., ), debt bondage and unreliable and often deceptive information pertinent to living and working conditions in the receiving countries(Emebet 2002, GTZ 2006). Migrant women who work as housemaids may also be liable to harsh treatments by their masters who often withheld their salaries (and sometimes their passports too) to curtail free movement of their employees in search of better opportunities (Emebet 2002, Regt 2007). Women who experience trafficking generally come from areas where employment opportunities are meagre and hence they depend on others for basic resources. Such women often migrate anticipating favourable work ground in countries of destination but are ultimately trapped in a situation of forced marriage or prostitution, domestic work and slavery. Unauthorized women migrants are especially vulnerable to such conditions. Generally, women are also paid less in the labour market. Migrant workers are generally considered part of the informal sector with little or no legal protection under labour laws of host countries exacerbating the exploitation of domestic workers (GTZ 2006). This is possible in the wake of weak or inexistent institutions that regulate private employers (ILO 2008, Jureidini 2003).

\section{The challenges of re-integrating returnees}

Reintegration of returnees is often considered as the final stage of migration. Migrants may decide to return home based either on their free will (following termination of contacts by employers) or forced deportations by authorities in destination countries. The latter is often common with illegal migrants (ILO 2003). The return home is often uneasy one and requires social and psychological adjustments. This is 
particularly true with women migrants with experiences of physical harm or sexual abuse. Reintegration is therefore usually problematic because of possible rejections by parents, friends and communities. Rejections may translate into denial of social support to returnees or even stigmatizations (Ibid 2003, Birke et al 2009). Returnees may cope with this situation of isolation by adopting various mechanisms including alcoholism, excessive smoking, and consumption of narcotic drugs (IOM 2006). Others may successfully adjust to the situation and engage independent income earning activities in home countries but the transition is often never smooth and policy makers in developing countries should make adequate note of the complex nature of migration and its challenges (ILO 2003). Even if returnees might succeed in securing employment opportunities back home, such opportunities make little difference in their livelihood as they engage in low profile jobs. Chances for them to receive skill development training are meagre and those who open their own small businesses often lack the necessary entrepreneurial skill to prosper. Hence re-integration problems and the challenges to survive economically could force many of the returnees to ultimately consider migrating again for domestic work abroad (Ibid 2003).

In recent years, international labour migration has become a top socioeconomic and political issue worldwide. It has in deed now become headline news in the global media as thousands of African migrants from countries particularly in the horn of Africa region make a risky journey overseas following conflict, poverty and bad governance in their respective countries. Africa currently exhibits rapid population growth which is not supported by commensurate economic achievements to ensure viable livelihoods for its youth. This has led people to look for alternative means of survival elsewhere across the globe. Their exodus abroad is expedited by smugglers and criminals who arrange their movement through corrupt practices of preparing false identifications and bribery (Global Initiative against Transnational Organized Crime, 20I4). As a result, extensive multidisciplinary and inter-disciplinary research needs to be conducted to epitomize the root causes, identify the economic, social and political underpinnings and policy implications of international migration. This study is intended to contribute to the efforts of building a body of literature on such a pertinent issue and inform policy makers about the way forward.

\section{Data Source and Methods}

The study was conducted in Mekelle town, which is the capital of Tigray regional state in northern Ethiopia. It is located about 780 kilometres north of Addis Ababa. According to the central statistics authority (CSA 2008) it has a total population of 215 ,
914 of whom 104, 925 are men and 110,989 are women. Majority of the people $(96.2 \%)$ belong to Tigray ethnic group while other groups constitute the minority (e.g. Amara $2.26 \%$ and all other ethnic groups make up $1.54 \%$ of the population). Tigrigna is the dominant language spoken by over $95.5 \%$ of the people. In terms of religion, the bulk majority (over $92.6 \%$ ) is Orthodox Christians and a little over $6 \%$ are Muslims (Ibid 2008).

This paper is based on a qualitative study which took place in Mekelle Town of Tigray Regional State, Northern Ethiopia. The study combined both primary and secondary data. Primary data was obtained with the help of Focus Group Discussions (FGDs), SemiStructured Interviews with Key Informants and Case Studies (individual story telling) in which women elucidated their experiences under different contexts. A purposive sampling of illegal migrants women who have had migration experiences in the Middle East (particularly, in Yemen, Saudi Arabia, Bahrain, Lebanon and Kuwait) were considered for the study. Since a consolidated list of returnees was not available in the city administration, the author identified women participants through informal inquiries in all directions of the research site. Personal acquaintances with some ex-migrants were a crucial step forward in the sample selection. Those identified were then able to suggest potential participants based on a set of criteria established by the researcher including age, migration experience and current socio-economic status. A total of 134 returnees were finally suggested although only $50 \%$ (i.e. a total of 67 women returnees were considered for the study due to resource limitations. Six FGDs (each consisting of 7 members) and 25 women Key informants from different age categories and with varying level of exposure to migration were involved. They supplied information regarding their experiences in Arab countries, their decisions to migrate and resettle and the accompanying challenges and opportunities. Four of the six focal groups were homogeneous while the remaining two comprised mixed discussants. Twelve in-depth interviews were also conducted to look into specific case examples. Questions raised during the interview include I) what were the main reasons for the onset of migration? 2) How was the choice of countries made? 3) Who was involved in the decision making process 4) what were the challenges before and after migration? 5) How has migration affected your overall livelihood and life style? Secondary data was also obtained from reports, archives and review of literature. The data was finally qualitatively interpreted and presented in this paper in the form of narrative exposition. The responses obtained from those who participated in the study were organized and analysed against existing literature and grand theories on migration. 


\section{Results}

\section{Pull and push factors}

Migration to Arab countries by Ethiopian women takes two forms: legal and illegal. The former is exercised by public and private employment firms under the auspices of the Federal Ministry of Labour and Social Affairs (MoLSA), Ethiopia, while the latter is a process undertaken by illegal traffickers. In the post 1991 period, the freedom of movement guaranteed by the new government in Ethiopia has encouraged the migration of a huge number of people to other countries in search of better livelihood. As a result, thousands of unskilled labourers have made their way to the Middle East and the trend is increasing even today. As Regt (2007) also noted, illegal agencies for employment of women domestic workers and brokers operate under cover as regulatory mechanism by state machineries is still weak.

Recruitment of migrant workers takes place in the context of a series of pressures and active involvement of family members and friends usually on the basis of misconceptions about the nature of work environment and amount of salaries earned in host countries. In the countries of destination, it is often the case that Ethiopian women work as domestic workers rather than care givers while men work as drivers, guards, construction labourers and waiters ( $\mathrm{KI}$ with Birtukan, age 32, Mekelle town, I8 Dec, 20I2]).

The most prominent push factor for mass migration from northern Ethiopia is poverty. Many of the informants and focus group discussants argued that unemployment was the principal driving force in their migration. Some dropped out before completing high school for academic and non-academic reasons; and the chance of getting hired in the civil service was extremely low as they were not well qualified to fit the requirements of white collar jobs. Even those who graduate from universities often find it difficult to secure employment opportunities. Over the past two decades there has been a boom in the number of private and public universities and colleges across the country. However, the supply of trained manpower is not commensurate with the demands in the job market. Others have been forced to migrate while still in school in the wake of extreme poverty caused by death of bread earners that threatens survival of the entire family. Grown up children often felt the moral responsibility to be independent and support the family economically if one or both parents die (FGD with women returnees, Mekelle town, 17 December, 20I2). One informant said, "I wish to die than see my little brothers and sisters suffer before my eyes." In relation to this, Abebai , age 35 also had the following to say:

"I migrated to Dubai in 1994 when I turned 19. I was in grade 12 and was not really a bad student in school. Unlike my friends who were not serious enough, I paid due attention to my studies and had no time to other things in spite of all the challenges and temptations. I was really progressing well in my studies when my father died following a short period of illness. He was the one who fed the entire family of 6 . As the eldest child, I felt I had to do something to maintain survival of the family. I boycotted my studies immediately and looked for a way out. My mother sometimes worked in private homes as a servant to earn some money but it was not enough. That's how I decided to migrate to Dubai" (IDI with Abeba, age 35, Mekelle town 29 December 20I2).

The regional government attempts to tackle problems of youth unemployment through a series of intervention measures including small and microenterprises, cooperatives, and the provision of loan services as well as training to mention just a few. This happens in the wake of growing criminal activities especially in towns. However, the overarching perception and attitude among the youth is that working in foreign countries brings more money in less time.

Those who have tried their luck by opening small enterprises for petty trade complained about the lack of a good financial return even though they used their potential to the fullest. Many did not succeed much apparently because of a number of factors not least the lack of adequate training and poor saving culture. They thought migrating to Arab countries would bring easy money in the shortest time possible. In the words of one key informant, "Why should one decide to languish in poverty running small shops here while others go overseas and comeback with glittering jewelleries and a good some of money?." This narrative is supported by Mihret's story:

"I graduated from Addis Ababa University with BA in management in 2007 but could not get a job. So, I had to return home and wait for my chance. Then, I was asked to join a cooperative business organized by the administration for the unemployed youth. First, I was reluctant, but later I was persuaded by my family to accept the offer, which I finally did. So, I joined a small group and we started running a kiosk together. We started to get some profit but it was small and frustrating. In the meantime, one of our neighbours who stayed in Riyadh (Saudi Arabia) came and everybody talked about her. She always wore beautiful dresses and brought a lot of gold. She was treated well everywhere in our neighbourhoods and we were all jealous. I decided to migrate on my own without even consulting anybody. After a lot of obstacles, I made my way to Beirut but alas I was deported within 7 months before I even started to make good money" (IDI with Mihret, age 28, Mekelle town, 24 December, 20I2). 
Families overburdened with loans are obliged to send their children to Arab countries to help them deal with the problem. To engage in low profile jobs such as janitorial work or trash collection in one's own neighbourhood is embarrassing especially for literate women regardless of the amount of income. In addition, the essence of proper work ethic is not well developed. There are some attitudinal problems among the youth although situations tend to be gradually improving in recent years following government sensitizations and unbearable economic hardships (FGD with women returnees, Mekelle Town, I5 December, 2012).

In addition to the economic incentives, informants also indicated that the need to migrate was motivated by mere curiosity to explore the world. This is often triggered by their exposure to the international media which depicted a different life style, cleanliness, and beautiful skyscrapers in the more developed countries including the oil rich Gulf States. The social honour and prestige given to diaspora community at home is also an important factor. Those with many years of international experience often enjoy better privileges and respect upon their return home. The overall attitude is that that the more you stay overseas the more you are respected by the local community (KI with Mahlet, age 28, Mekelle town, 21 December, 20I2).

Social problems such as dissatisfaction with marital life and social rejection can also serve as push factors. For example, upon divorce women are often frustrated to stay in the same traumatic and stressinducing environmenti and prefer to go abroad leaving behind their children with their parents. After divorce, it is considered shameful and embarrassing to return to the parents' house. Hence women often explore other ways of dealing with divorce including migration. In the likely event of unsuccessful journey, they might even decide to take up other livelihood options such as prostitution in places (like Addis Ababa) that are far away from their home towns (FGD with women returnees, Mekelle town, I4 December, 20I2).

According to some informants, the need to work and keep oneself busy can also trigger migration even if poverty is not a serious concern. Some of the returnees asserted that they migrated to the Gulf States not because their families had a dire need for money to survive but out of sheer quest for an active engagement in productive activities. Some informants said, life was "too boring" when they were idle (KI with Tirhas, Age 34, Mekelle town, I8 December, 20I2).

\section{Pattern of decision making during migration}

Migration to other countries normally requires careful planning and access to organized information about the destination. According to focus group discussants, this money comes from different sources in the form of credit, family support and sale of assets. Others may involve in some sort of transitory prostitution as part of a long term plan to cover migration related costs ${ }^{\text {iii. }}$ Brokers who facilitate their travel abroad often demand money or sexual favours (or both) from potential migrants as part of a deal (FGD with women returnees, I5 December, 20I2).

Women who plan to move out are often keen to gather information from returnees regarding the procedures involved, the amount of cost incurred as well as the challenges and opportunities in countries of destination. Returnees who build valuable fixed assets are taken as models and approached for information sharing. Without proper social networking entry into host countries, resettling and securing employment becomes difficult if not impossible. However not all the information provided is taken for granted. According to informants, information acquired from friends often does not depict the true picture of the realities in Arab countries, nor are those who tell the truth adequately trusted. In fact, those who spend time discussing more about challenges are considered jealous and harbouring malicious intentions. Those who capitalize on the negative sides are often crossexamined with questions like, "if life is difficult in those places, how come you decide to go there? How come you bought nice clothing and jewelleries? etc.," Sometimes, despite warnings, women decide to migrate and experience things for themselves. With regard to choice of the type of migration, mixed responses were obtained. While some of the informants indicated that they did not have adequate information about the distinction between the legal and illegal channels, others said they knew about the legal course but did not opt for it because it was time consuming and bureaucratic. Many of them however stated that they regretted their decision to go by illegal means as this resulted in being alienated putting them in constant fear of deportations. In recent years, the government media has also massively sensitized women against the negative consequences of illegal migration into Arab countries although often without much success (FGD with women returnees, Mekelle town, I5 December, 20I2).

During the time of the Derg regime (i.e. up until the end of the 1980's) where freedom of movement of citizens was largely curtailed by government policies, people used different outlets to migrate. A common practice in Tigray was to join the then Guerrilla movement in the remote areas and defect to neighbouring countries like Sudan, and finally crossover to the Gulf States. The story of two close friends illustrates this point: 
Hansa and Mulu (Age 18 and 19 respectively) were long-time friends and joined the same school for their primary education. Hansa's father owned a shop and was doing well in business. On the contrary, the former belonged to a much poorer family. Her mother was an unemployed housewife. The only asset her father owned was a sewing machine and his income as a tailor was hardly enough to support a family of 8 . Hansa was married off to a person whom she did not personally know. The wedding took place without her consent much to her disappointment. Her husband took her to his home village but she could not accept such a forced marriage at that young age. So, she returned to her parents the next morning weeping and complaining. But she was beaten by her dad and sent back to her husband. The same trajectory of deserting her husband took place on several occasions but her parents' reaction was the same. Out of sheer dissatisfaction with her marital life, she persuaded her friend Mulu to flee abroad. As they both did not have enough money, they decided to join the armed struggle in rural Tigray and saw possibilities to escape from there. After a short time stay there, they left the army and travelled to Sudan from which they made their way to Saudi-Arabia. In a matter of few years, Hansa moved to America where she still lives with her new husband. Mulu was not as lucky. After years of illegal stay in Saudi Arabia, she was deported back home and she now runs a small hotel business in Mekelle town" (IDI with Mulu Aregawi, age 42, Mekelle town, December 24, 20I2.)

According to informants, most would prefer to migrate to countries like Saudi-Arabia and United Arab Emirates compared to other countries(such as Yemen and Kuwait) owing to a relatively better living and working condition(higher salaries). Saudi Arabia was also preferred especially by Muslim women because they could formally use Hajj and Umurah pilgrimage as a favourable instrument without having to risk their lives trudging through deserts and sea waters (FGD with women returnees, Mekelle town, December I3, 2012). As GTZ (2006) also noted, women are not allowed to travel to the holy places in Saudi Arabia alone and hence they usually pay men to process their visas as their close associates either as wives or relatives. Dubai has also attracted more interest especially among younger women because of a western type life style which many find suitable and easy to adapt to. Countries like Yemen are poorer and provide fewer opportunities and hence are used by migrants as transit destinations.

\section{Life in the Gulf States: opportunities and challenges}

Informants asserted that their migration to the Gulf States presented a number of opportunities and challenges. An overwhelming majority of the informants indicated that their expectations were much higher than actual achievements. Firstly, living in a completely new physical and social milieu has never been easy for many fresh migrants. Generally migrant women reported a partial or complete loss of identity as they adapted to a new Arab culture and integrated themselves into the host community. Moslem migrants were in a better condition owing to the similarity in religion which facilitated better integration into the system. Christian women on the other hand had to face the challenge of not only learning a new language but also a change in religious identity into Muslims and adopting Islamic norms and value systems (i.e. new names, dressing style and code of conduct to mention just a few) ${ }^{i v}$ With regard to the dressing code, an informant who faced culture shock upon arrival stated:

"As soon as I arrived there, I was asked to weir a veil, an apron that covered all my body. What irritated me most was the fact that I had to wear a black apron. In my culture, a person appears in black clothing only when relatives or family member die; especially during the period of mourning" (IDI with Helina, age 27, January I2, 2013).

But whether they are Muslims or Christians, the nostalgic feelings caused by separation from loved ones (often for the first time in their life time) create a sense of discomfort and depression. Many informants reported of a continuous state of crying as they called home and talked to their parents and kids on the phone (FGD with women returnees, Mekelle town, January I5, 2013).

Migrants are in principle bound to work for a specified number of hours per day for which a certain amount of payment/wage is assigned. However, contracts are easily breached by many employers and they are asked to work for an indefinite period of time for the same amount of money. Women may be forced to work in other homes other than that of the employers' without overtime remunerations. Sometimes monthly payments are either delayed or are simply denied altogether. Most of those who migrated illegally are locked up in a situation where communication with fellow country people is forbidden or restricted. One informant has characterized this situation as, "A kind of modern slavery....it feels as if you are always caged or imprisoned" (KI with Almaz, age 30, Mekelle town, January I8, 20I3).

Most informants reported that they worked as maids taking care of cleaning and janitorial activities. But it is also often the case that they became sex slaves in the hands of their masters- a situation which is not reported for fear of persecution and deportation (FGD with women returnees, January I6, 20I3). In 
addition, Mohammed \& Joy (2002) have also documented the situation with Ethiopian women who first migrated to Djibouti and other Arab countries for work but ultimately ended up in prostitutions.

Informants also reported that there were occasional physical and psychological harassments especially by housewives who sometimes become jealous when their husbands treat them well. According to focus group discussants men generally tend to be less harsh on women domestic workers. Any extra-ordinary relations between Arab men and their maids or a mere suspicion of such eventualities could lead to the physical torture of domestic workers by wives reportedly because of jealousy. One informant called Lemlem, aged 28, described her situation as follows:

"Moments after I arrived in Riyadh, Saudi Arabia, I had to take up the usual cleaning services as a maid in the house of a rich family. The first few months were especially harsh for me as the entire family was discontent with my performance. Gradually the husband started to feel pity for me and became more kind as the days passed by. He never treated me as a maid. On the other hand, his wife's fury increased and I could sense feelings of jealous in her for no apparent reasons. She started to harass me repeatedly and warned me that she would end my life if I did not improve my work efficiency. 6 months after I took up the job, my employer's wife came to me one afternoon and suddenly started shouting at me. I stood confused as I did not understand what she was saying. She pointed at the sofas and window glasses complaining about the dirt. Feeling guilty, I started to clean them up again but she was so impatient that she hit me with a bottle filled with water. She hit me on my ribs and it was painful. I wept bitterly that day. The next morning, I decide to go back home because I thought I might end up being killed in a foreign country. Days after that event, I asked permission to go home pretending that my mother was ill. I came home and never returned. I ran away with my tail behind my legs never to risk my life again. I need to live at least for my daughter" (IDI with Lemlem, aged 28, Mekelle town, January 19, 2013.)

Other Informants also raised incidents of severe torture and barbaric killings of Ethiopian women in Arab countries. It was also reported that some women even committed suicide by throwing themselves down from buildings. The protection of women's rights in those countries is far from adequate especially with illegal migrants. As pointed out in earlier sections, even if there are legal provisions to protect their rights, women either take it for granted that such abuses are expected ${ }^{v}$ or are just afraid of reporting it for fear of deportation to their home countries which brings more psychological pain and social rejection (FGD, with women returnees, Mekelle town, December I5, 20I2).

Despite the aforementioned problems, migrants make some economic gains which otherwise would have been impossible to attain in their place of origin. The magnitude of material and financial benefits to be achieved as an illegal migrant in those countries depends on a number of factors. But informants normally attribute successes and failures to mere luck. People can earn up to 3000-5000 Birr/month (USD 150-250) or more depending on the type of work, hours spent on duty and location. Migrants are often given food and shelter in addition to their basic salary which gives them the leverage to save more money. In addition, their exposure to modern technologies, new culture and life style in the host countries broadened their horizon of thinking multilaterally putting a limit on their own ethnocentric understanding of other cultures. Competitions amongst themselves also triggered the motivation to succeed in life (KI with Abrehet, age 40, Mekelle town, I8 December, 2012).

\section{Life as ex-migrants}

Life as returnees brings ex-migrants both an opportunity and a challenge depending on their financial status. Reintegration into one's own society is often a bumpy road for ex-migrants. Return from the gulf as "deportees" by itself creates an unfavourable psychological condition often putting personal integrities at stake. Local communities hold negative attitudes especially towards those who fail to accumulate a good sum of money despite several years of domestic work abroad ${ }^{\mathrm{vi}}$. In ordinary narratives coming back home from overseas without meeting one's own predetermined goals implied the lack of intelligence and surrender to challenges in life. The overall attitude is that one should never consider concede defeat but rather should be fast enough to use every option at his disposal (including cheating) in order to succeed in life. According to informants, many ex-migrants considered going back to the Gulf States to try another chance not because they enjoyed life in exile but in order to elude rumours and criticism from friends and families. The rumours that run against deportees are related to their being unfit for the jobs, links to criminal activities such as theft, or being infected to incurable diseases (mainly HIV AIDS) none of which may indeed reflect the true reasons for return home (FGD with women returnees, Mekelle town, I4 December 2012). One informant who was deported only after a few months of stay in Saudi Arabia said:

"At the outset, I really did not have the courage to look into the eyes of my friends, family members and other community members because I could feel a 
sense of loathe and contempt running through their minds and hearts. So, I decided to spend much of my time at home sleeping. Now situations are better because with new arrivals of deportees in the neighbourhood, I am now part of history and people don't talk about me anymore. I feel pity for the new arrivals because they would be in the same situation as I was before" (KI with Alem, age 3I, Mekelle town, 19 January 20I3).

On the other hand, there are also some success stories. There are women who opened up small business ventures in town and doing well in business. Given the limited financial resources of ex-migrants, large scale investments are still remote possibilities. Most tend to have risk aversive behaviour and hence don't spend all their savings in any one area of investment. The accumulation of precious items such as gold is pursued as an insurance scheme to avoid complete loss of livelihood just in case business investments fail to achieve desired economic targets ${ }^{\text {vii. }}$. Most of those who opened up their own businesses established small coffee houses and bars in rented container houses although they find it hard to cope with increasing rent charges, administrative restrictions $^{\text {viii }}$ tax payments and customers behaviours. Often interactions with male customers end up in request for sexual engagements. As a 'side business,' some women also informally operate as sex workers based on specific demands by customers. Others are engaged in illicit trades under the cover of darkness (KI with Tsehaynesh, age 28, 22 January 20I3).

To sum up, it is evident from the study that mass migration of women domestic workers have become rampant in recent years and that Arab states are selected as principal destinations not only among those who are illiterate but also among graduates. Hence, youth unemployment is the main push factor while social pressures confound the problem further. Information flow has been limited and many women were often more exposed to information about the positive sides of migrating to the Gulf-states. Generally, migration has brought opportunities for better income and livelihood but it has also its own cost: dispersal of family, culture-shock in foreign countries, domestic violence and isolated life and depression to mention just a few.

\section{Discussion}

The study found out that the decision to migrate is often an uneasy task. Long distance mobility often takes a slow but enduring process as decisions have to be based on strings of information from various sources. The decision making process is likely to engage not just individual migrants but also entire households. In view of the "new economics of migration" model such collective rational decision making helps reduce pressure on family income or minimize financial constraints on family productive activities (King 20I2).

Informants have identified a multitude of factors that triggered their decision to migrate into the Gulf States. They stated that youth unemployment is a major push factor. According to informants, international mobility is generally considered one of the best options for access to lucrative income and sending remittances back home. This links up with the neo-classical models of international migration which explains onset of migrations in terms of wage differentials and the decision to maximize income by individual actors (Massey et al 20ll). However, according to respondents, it is hardly possible to make sharp distinctions between push and pull factors because opportunities in countries of destination as pull factors were also mentioned as crucial. In fact, Piore (1979) argues that that pull rather than push factors are primarily responsible for international migrations. This has something to do with the demand for cheap labour in richer countries where dual market structures operate: a primary market characterized by a viable, secure and lucrative jobs for native workers; and a secondary labour market characterized by unskilled labour, marginal wage, unsustainable bluecollar jobs (ibid 1979). According to Massey et al (20II), this happens because there are some poorer regions where capital is scarce whereas labour is plenty and hence the wage remains low. In recipient countries that are much wealthier than the migrants' countries of origin it is often the case that labour is scarce and capital is present in abundance and hence the wage is correspondingly high. The findings of the study demonstrate that most of the women migrants worked as low wage domestic jobs because natives are reportedly reluctant to take up such low-profile jobs. The low level of training of Ethiopian women migrants also prevents them from competing for the more decent jobs in the manufacturing and civil service sectors.

According to informants in the study area, migration to Arab countries presents its own challenges and opportunities. Although a significant number of migrants encounter life threatening experiences in those countries, the livelihood change of those that were successful especially upon return home should not be overlooked. As King (20I2), also pointed out although myriads of migrants experience exploitation and brutal treatment in terms of work burden and remunerations, there are others who ensure economic viability and livelihood improvements. 


\section{Conclusion}

Poverty and unemployment as push factors play a significant role in migration especially among women and young girls from poor regions of Ethiopia to the Arab states. In northern Ethiopia poor women have limited access to education which in turn affects their access to income through employment in the formal sector. Unemployment due to low level of literacy and training will then further exacerbate their poverty. Therefore the two operate in a vicious circle forcing women to take life-threatening options to survive.

The present situation of migrant women calls for strategies to protect and empower women migrants in the form of information dissemination and awareness creations about international laws and conventions as well as women's rights. In addition, there is a need to come up with sound legal provisions against trafficking and improving women's access to employment opportunities in their places of origin. In the absence of such undertakings, it is difficult if not impossible to curb the cycle of illegal migration and put an end to women's sufferings thereof. Projects hitherto put in place are not satisfactory. In fact, apart from the scanty resources being used by the government to provide the youth with jobs, initiatives from Civil Society Organizations and local NGO are rare and far between.

\section{References}

Adams, R. 2005. Remittances, poverty and investment in Guatemala, in SCHIFF, M. and Ç. Ozden (eds.), International migration, remittances, and the brain drain, World Bank, Washington, D.C.

Birke, A. Charlotte H. Atalay A. Samuel, P., \& Rob Whitley. 2009. Migration and mental health: A study of low-income Ethiopian women working in Middle Eastern countries: SAGE

Central Statistics Authority (CSA). 2008. Summary and statistical report of the 2007 population and housing census. Federal Democratic Republic of Ethiopia Census Commission Addis Ababa, Ethiopia

Castles, S. and Miller, M.J. 1993. The Age of migration: International population movements in the modern world. London: Macmillan

Cresswell, T. 2006. On the move: Mobility in the modern western world. London: Routledge.

Datta, P. 2004. Push-Pull factors of undocumented migration from Bangladesh to West Bengal: A perception study. Dakka

Dorigo, G. \& Tobler, W.1983. Push-Pull migration laws. Association of American Geographers: Taylor \& Francis, Ltd

Global Initiative against Transnational Organized Crime. 2014. Smuggled futures: The dangerous path of the migrant from Africa to Europe available at

http://www.globalinitiative.net/download/globalinitiative/Global\%20Initiative\%20-

\%20Migration\%20from\%20Africa\%20to\%20Eur ope\%20-\%20May\%2020I4.pdf accessed I2 June 2015.

GTZ. 2006. Trafficking in Women, Forced Labour and Domestic Work in the Context of the Middle East and Gulf Region. Working Paper: Anti-Slavery International

Hochschild, A. 2003. Love and gold. In B. Erenretch and A.R. Hochschild Global Women: nannies, maids and sex workers in the new global economy. London, Granta Books, I5-30

ILO. 2003. Preventing discrimination, exploitation and abuse of women migrant workers: An information Guide Booklet 5 Back Home: Return and Reintegration. Gender Promotion Program International Labour Office Geneva 2008. Promoting the rights of women migrant domestic workers in Arab States: The case of Lebanon. Issue Brief.

International Organization for Migration (IOM). 2006. Breaking the cycle of vulnerability: Responding to the health needs of trafficked women in East and Southern Africa Pretoria.

Isaksen, L. Arlie, R. 2008. Global care crisis: A problem of capital, care chain or commons? American Behavioural Scientist, 52(3)

Jureidini, R. 2003. Trafficking and contract migrant workers in the Middle East, International Migration, 48(4): I42-I63

King Russell. 2012. Theories and typologies of migration: An overview and a primer,

Willy Brandt Series of Working Papers in International Migration and Ethnic Relations 3//2 available at https://www.mah.se/upload/Forskningscentrum/M IM/WB/WB\%203.12.pdf accessed I5 June 2015.

Lucas, R. 2004. International migration to the high income countries: Some consequences for economic development in the sending countries, Annual Bank Conference on Development Economics.

Martin, S. 2007. Women, migration and development: Transatlantic perspectives on migration. Institute for the Study of International Migration, Walsh School of Foreign Service, Georgetown University

Massey. Douglas, Arango, Joaquin, Hugo, Graeme, Kouaouci, Ali, Pellegrino, Adela, and

Taylor, J. Edward 201I.Theories of international migration: A review and appraisal, Population and Development Review, Vol. 19(3) 43I-466

Regt, D. 2007. Ethiopian women in the Middle East: The case of migrant domestic workers in Yemen. 
Paper for the African Studies Centre Seminar, University of Amsterdam

Steady, F. 2006. Women and collective action in Africa: Development, democratization, and empowerment with special focus on Sierra Leone. Palgrave Macmillan New York

Shuval, J. 200I. Migration, health and stress. In William

C. Cockerham (ed.) The Blackwell Companion to Medical Sociology. Blackwell Publishers

\footnotetext{
i All names indicated in this report are fake in order to maintain privacy of informants

ii Divorced women are often not properly valued in the society. The chance of re-marrying is very slim especially if they have many children. Divorce is perceived as bad luck and women who are divorced are considered a disgrace and burden for the family. Hence the pressure to migrate is high

iii One of the key informant stated that she worked in a bar for 3 months (never referred to her work as prostitution because she felt embarrassed about it)

iv Northern Ethiopia is home for conservative Christian tradition making it very difficult for migrants to internalize Islamic norms and values.

${ }^{v}$ This is not exceptional to migrants in Arab countries. Even within Ethiopia, women (especially rural women) who work
}

Ramirez, C., M. Garcia Dominguez and J. Miguez Morais, 2004, "Developing a framework to understand the relationships between migration, gender, remittances and development", United Nations International Research and Training Institute for the Advancement of Women,

Suter, B. 2005. Labour migration in the United Arab Emirates, Malmo University

UNHCR. 1990. Rami Policy on refugee women. Geneva: UNHC

as house maids tend to be submissive and experiences of abuse by employers are common

vi It seems evident that the rhetoric of staying abroad is often associated with becoming rich. Those who don't fit into this framework are perceived as extravagant and hence the community usually shows less respect to them

vii Gold or investment in fixed assets is preferred as a result of inflations and decreasing value of local currency against the Dollar

viii Informants for example stated that there were times when the administration forbade running businesses in small container houses. In addition, coffee house owners have recently been told not to sell alcoholic beverages unless otherwise they have special permits. 